\title{
Beating the heat: ecology of desert bobcats
}

\author{
John Draper ${ }^{1}$, Torrey Rodgers ${ }^{2}$ and Julie K. Young ${ }^{2,3 *}$ (B)
}

\begin{abstract}
Background: Relative to temperate regions, little is known about bobcats (Lynx rufus) in the Sonoran Desert portion of their range, in part due to the difficulty of sampling an elusive carnivore in harsh desert environments. Here, we quantify habitat selection and evaluate diet of bobcats at Kofa National Wildlife Refuge, Arizona, USA, using multiple sampling techniques including GPS telemetry, camera traps, and DNA metabarcoding.

Results: Home ranges during the hot season were smaller than during the cool season. Camera trapping failed to yield a high enough detection rate to identify habitat occupancy trends but third-order resource selection from GPS-collar data showed a preference for higher elevations and rugged terrain at lower elevations. Diet composition consisted of a diverse range of available small prey items, including a higher frequency of avian prey than previously observed in bobcats.

Conclusions: Desert bobcats in our study maintained smaller home ranges and primarily consumed smaller prey than their more northern relatives. This study illustrates the benefit of employing multiple, complementary sampling methods to understand the ecology of elusive species.
\end{abstract}

Keywords: Bobcat, Lynx rufus, Meta-barcoding, Home range, Resource selection, Habitat selection

\section{Background}

Information on ecological traits of carnivores, such as habitat use, home ranges, and diet, can improve our understanding of necessary habitat and prey requirements for conservation and management. These traits may depend on whether the species is a specialist or generalist [1]. While generalists exhibit flexible patterns in these ecological traits, some species, like bobcats ( $\operatorname{Lyn} x$ rufus), need habitat with sufficient cover to allow for successful stalking and capture of preferred prey species and home ranges large enough to provide adequate hunting grounds [1-3].

Bobcats occur from northern British Columbia in Canada to central Mexico and have been most heavily studied in the northern portion of their range, where they show a clear preference for forested habitats [4-6].

\footnotetext{
*Correspondence: julie.young@usu.edu

${ }^{3}$ U.S. Department of Agriculture, National Wild life Research Center -

Predator Research Facility, Millville, UT 84326, USA

Full list of author information is available at the end of the article
}

In the northern and more mesic portions of their range, forested habitats provide suitable hunting grounds for stalking and ambush hunting [7]. In the more xeric southern portions of their range, where forested habitat is rare, bobcats tend to prefer wetlands when available or dry washes that provide cover to aid in prey stalking and ambush [3]. However, limited information exists on habitat use by bobcats in deserts, especially those lacking wetlands.

Bobcats display temporal movement patterns linked to prey vulnerability and temperature, whereas homerange placement and utilization are influenced by inter- and intra-specific factors. Bobcats are most active during crepuscular periods of the day, matching the activity of their prey [8]. Bobcats travel the longest distances at night, typically when it is coolest, and limit movement during the day $[9,10]$, particularly in hot climates. Male bobcats typically have larger home ranges than females to maximize breeding opportunities. Female bobcats show minimal home-range overlap with each other, and temporal partitioning when 
there is spatial overlap [3, 7, 9], to maximize resource monopolization and minimize interactions.

Bobcats most commonly consume lagomorphs and rodents across their range [11]. Studies have shown prey specialization by bobcats on either lagomorphs or rodents depending on interactions with sympatric competitors. In addition to their preferred prey, bobcats consume birds, mesocarnivores, and ungulates with regional variation in the relative abundance of these prey items in their diet $[11,12]$. Though bobcats show within-population specialization on particular prey items [12], they are capable of exploiting a wide breadth of potential prey as dictated by regional abundance, habitat variation, and interspecific competition with other carnivores $[11,13,14]$.

Studies of bobcats and other carnivore species face challenges associated with their elusive nature, relatively large home ranges, and low densities [15]. These challenges can be compounded in hot and harsh environments where additional precautions need to be taken to ensure animal welfare when conducting activities such as live trapping, which can then result in low sample sizes $[3,9,16]$. A second issue common in carnivore studies is that traditional diet analysis through morphological identification of undigested parts in carnivore scat can be biased towards larger more identifiable prey items and those for which indigestible parts are consumed [17-19]. These potential biases in how data are collected can limit or alter inference from studies on basic ecology of carnivores.

We studied bobcats at Kofa National Wildlife Refuge in the Sonoran Desert near Yuma, Arizona, USA. Our goal was to assess bobcat ecology in the desert southwest of the United States, including habitat use, home-range size, and diet composition. To evaluate habitat use and home-range size, we captured and fitted bobcats with GPS-collars, and deployed a cameratrap grid. To evaluate diet, we used next-generation sequencing-based metabarcoding to identify vertebrate prey items from bobcat scats [20,21]. This study utilizes a complementary and robust framework to best inform our understanding of carnivore ecology.

\section{Results}

\section{Trapping}

Three adult females and one juvenile male bobcat were captured and fitted with Global Positioning System (GPS) collars in February and March of 2017. All four animals yielded roughly 11 months of GPS-locations $(326 \pm 31$ days, $\mathrm{n}=4)$.

\section{Camera trapping}

Camera-traps were deployed for a total of 2506 trap days across 69 trap locations and yielded 230 photographs, comprising 96 discrete detection events, with each detection event typically containing multiple photographs. Individual identification was generally not possible from most camera-trap data given a lack of distinct variation in pelage and a high proportion of detections occurring at night, which resulted in images where sufficient sections of the body were rarely visible to determine spot patterns. Even so, we identified at least five different adult bobcats in our study area based on the camera-trap photographs, one of which was the collared male. We could not determine the sex of the remaining individuals from the angles of the photos.

\section{Home-range estimations and resource selection}

Home ranges for the three female bobcats averaged $16.0 \mathrm{~km}^{2}\left( \pm \mathrm{SE} 1.0 \mathrm{~km}^{2}\right)$, while the single juvenile male had an annual home range of $57.8 \mathrm{~km}^{2}$ (Table 1, Fig. 1). When considering the sexes separately (to account for differences in effect size), home ranges were $8.3 \mathrm{~km}^{2}$ smaller on average during the hottest 4 months (JuneSeptember, mean temp $\left.33{ }^{\circ} \mathrm{C}\right)$ of the year $(\mathrm{p}=0.058$, paired $\mathrm{t}$-test) relative to the coolest 4 months of the year (Table 1, November-February, mean temp $13.5^{\circ} \mathrm{C}$ ) [22]. The smaller home ranges observed during the hot season were completely contained within both the home range during the cool season and the total annual home range.

All variables included in the resource selection function models had low correlation with variance inflation factors of $<2$. The top resource selection function model included ruggedness, elevation, and season as well as interactions between ruggedness and elevation, ruggedness and season, elevation and season, and ruggedness, elevation, and season (Table 2). Bobcats were 1.68 times more likely to utilize rugged terrain and

Table 1 The 95\% kernel utilization density home range sizes for each GPS-collared bobcat at Kofa National Wildlife Refuge, for the whole year (All), for the hottest 4 months of the year (Hot season, June-September mean temperature $33^{\circ} \mathrm{C}$ ), and for the coolest 4 months of the year (Cool season, November to February, mean temperature $\left.13.5^{\circ} \mathrm{C}\right)$

\begin{tabular}{llcc}
\hline ID & \multicolumn{3}{l}{ Home ranges $\left.\mathbf{( k m}^{2}\right)$} \\
\cline { 2 - 4 } & All & Hot season & Cool season \\
\hline KBF02 & 15.2 & 10.6 & 19.4 \\
KBF03 & 17.3 & 13.5 & 25.0 \\
KBF04 & 14.4 & 11.7 & 16.1 \\
KBM01 & 55.8 & 42.0 & 121.6 \\
Average & 25.7 & 19.5 & 45.5 \\
Average females & 15.6 & 11.9 & 20.2 \\
SE of female HRs & 0.9 & 0.9 & 2.6 \\
\hline
\end{tabular}

The single male was a juvenile, whereas the females were adults 

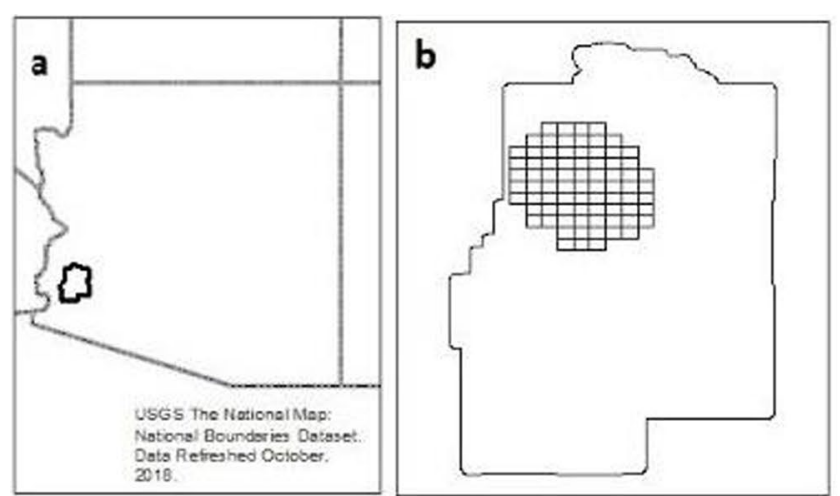

\section{Legend}

- Camera Locations

\begin{tabular}{|c|c|}
\hline & Sample Grds \\
\hline & $\mathrm{F} 02$ \\
\hline & F03 \\
\hline$x$ & F04 \\
\hline EDA & M01 \\
\hline
\end{tabular}

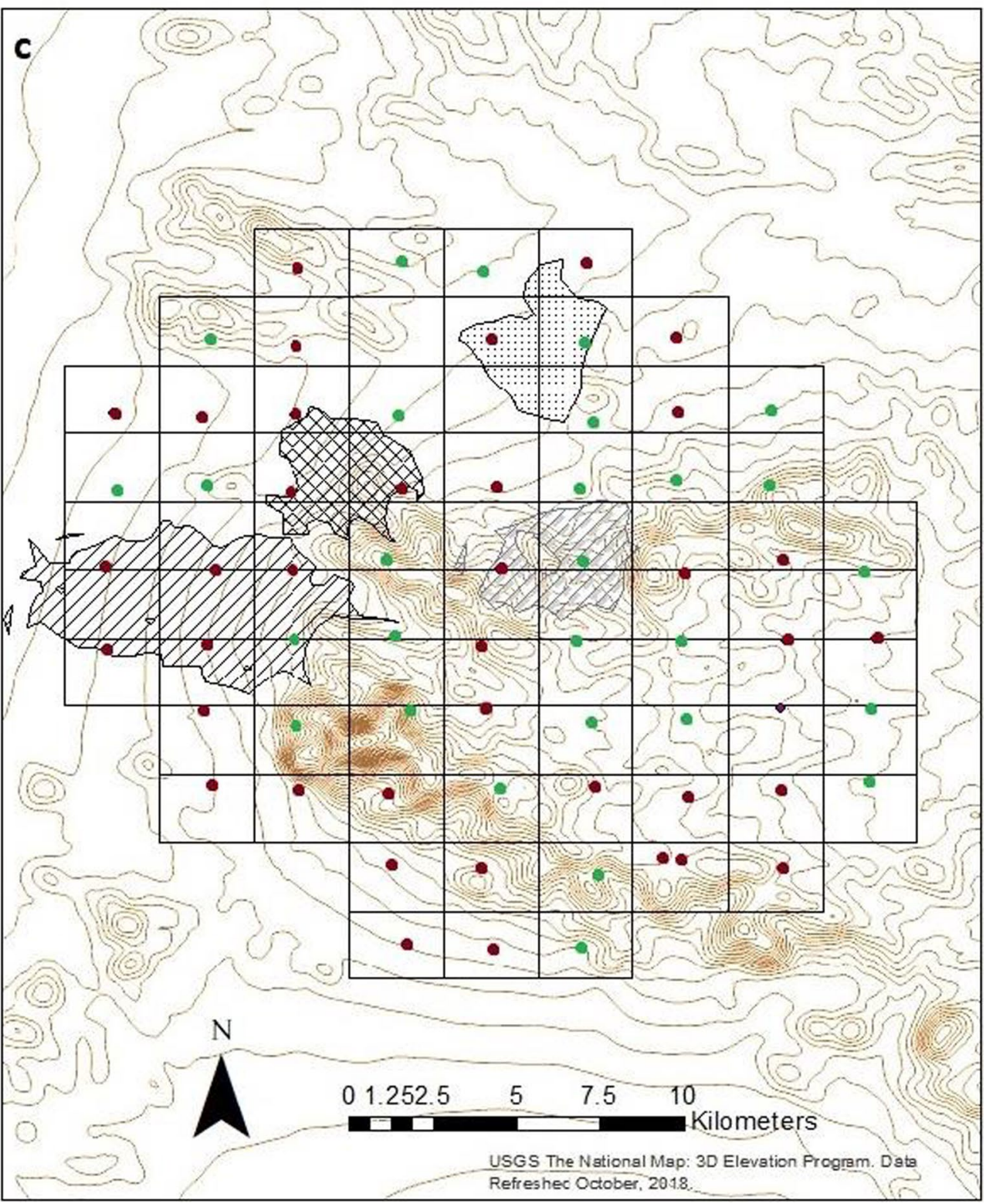

Fig. 1 a The boundary of Kofa National Wildlife Refuge, Arizona, USA, b the 2-km sampling grid within the boundary of Kofa, and $\mathbf{c}$ the realized placement of cameras within the 69 grid cells and the home ranges of four GPS-collared bobcats. Green camera locations had at least one bobcat detection. The map data was obtained from a freely available for use source 
1.22 times more likely to use higher elevations (Table 3, Fig. 2). The interactions between season and both ruggedness and elevation showed a slight decrease in usage during the hot season but with a large confidence interval widely overlapping zero (Table 3 ). Bobcats were also 0.15 times more likely to use rugged terrain as it increased in elevation. During the hot season their usage of rugged terrain as it increased in elevation was 0.53 times more likely (Table 3 ).

\section{Occupancy modeling}

The totality of the camera-trap grid averaged $129.5 \mathrm{~m}$ higher in elevation $( \pm$ SE $0.49, \mathrm{p}<0.001, \mathrm{t}$-test $)$ and 1.6 times more rugged (means 1.9 and 1.2, difference of $7.2 \pm$ SE 0.007, $\mathrm{p}<0.001$, t-test) than the home ranges of the collared bobcats. Despite this more diverse coverage of terrain variables, no models reached statistical significance or an $\mathrm{r}^{2}$ value $>0.09$ (Additional file 1: Table S1).

\section{Diet analysis}

A total of 51 presumed bobcat scats were collected, of which 39 yielded sufficient DNA for species identification. Of the 38 samples successfully sequenced, 31 were identified as bobcat and 7 were identified as coyote (Canis latrans). All 31 samples identified as bobcat amplified at the $12 \mathrm{~s}$ and $16 \mathrm{~s}$ markers.

Table 2 AlCc table for model selection of mixed effect models considered for 3rd order habitat selection by bobcats at Kofa National Wildlife Refuge, Arizona, from GPS-collar data obtained between February 2017 and January 2018

\begin{tabular}{|c|c|c|c|c|c|c|}
\hline Model parameters & $\mathbf{K}$ & AICc & $\Delta \mathrm{AICc}$ & AlCc weight & $\begin{array}{l}\text { Cumulative } \\
\text { weight }\end{array}$ & Log likelihood \\
\hline Rugged + Elev + Rugged ${ }^{*}$ Elev + Rugged*Season + Elev*Season + Rugged*Elev*Season & 14 & 32,134 & 0 & 1 & 1 & $-16,072$ \\
\hline Rugged +Elev + Rugged*Elev + Rugged*Elev*Season & 10 & 32,221 & 88 & 0 & 1 & $-16,116$ \\
\hline Rugged +Elev + Rugged*Season + Elev*Season + Rugged*Elev*Season & 12 & 32,567 & 434 & 0 & 1 & $-16,289$ \\
\hline Rugged + Elev + Rugged*Season + Elev*Season & 10 & 32,636 & 503 & 0 & 1 & $-16,324$ \\
\hline Rugged + Elev + Elev*Season & 8 & 32,709 & 576 & 0 & 1 & $-16,361$ \\
\hline Rugged + Elev + Rugged*Season & 8 & 32,731 & 597 & 0 & 1 & $-16,372$ \\
\hline Rugged + Rugged*Season & 6 & 32,839 & 705 & 0 & 1 & $-16,427$ \\
\hline Eleve + Elev*Season & 6 & 33,020 & 886 & 0 & 1 & $-16,518$ \\
\hline Rugged + Elev + Rugged*Elev & 8 & 36,878 & 4745 & 0 & 1 & $-18,446$ \\
\hline Rugged + Elev & 6 & 37,124 & 4991 & 0 & 1 & $-18,570$ \\
\hline Rugged & 4 & 37,159 & 5025 & 0 & 1 & $-18,595$ \\
\hline Elev & 4 & 37,277 & 5144 & 0 & 1 & $-18,655$ \\
\hline Null & 2 & 37,542 & 5409 & 0 & 1 & $-18,763$ \\
\hline
\end{tabular}

Table 3 Coefficients for the top mixed effect model for 3rd order habitat selection by bobcats at Kofa National Wildlife Refuge and the variance of the random effect of individuals on each. Parameter values were standardized to deviation from the values mean as a multiple of the standard deviation to aid in model convergence. The average, maximum, minimum, and standard deviation of both the elevation and ruggedness for the collected data before this transformation is reported below the model estimates

\begin{tabular}{|c|c|c|c|c|}
\hline Parameter & Estimate & S.E & Odds ratio & $\begin{array}{l}\text { Variance } \\
\text { of random } \\
\text { effects }\end{array}$ \\
\hline (Intercept) & -4.04 & 0.30 & 0.02 & 0.36 \\
\hline Rugged & 0.52 & 0.38 & 1.68 & 0.56 \\
\hline Elev & 0.20 & 0.05 & 1.22 & 0 \\
\hline Rugged:elev & -1.90 & 0.61 & 0.15 & 1.5 \\
\hline Rugged:hot & -0.06 & 0.33 & 0.94 & 0.40 \\
\hline Elev:hot & -0.07 & 0.50 & 0.93 & 0.98 \\
\hline Rugged:elev:hot & 1.26 & 0.66 & 3.51 & 1.74 \\
\hline Raw data values & Average & Maximum & Minimum & $\begin{array}{l}\text { Standard } \\
\text { deviation }\end{array}$ \\
\hline Elevation & 609.5 & 1110.6 & 421.1 & 128.6 \\
\hline Ruggedness & 3.5 & 78.4 & 0.03 & 5.4 \\
\hline
\end{tabular}



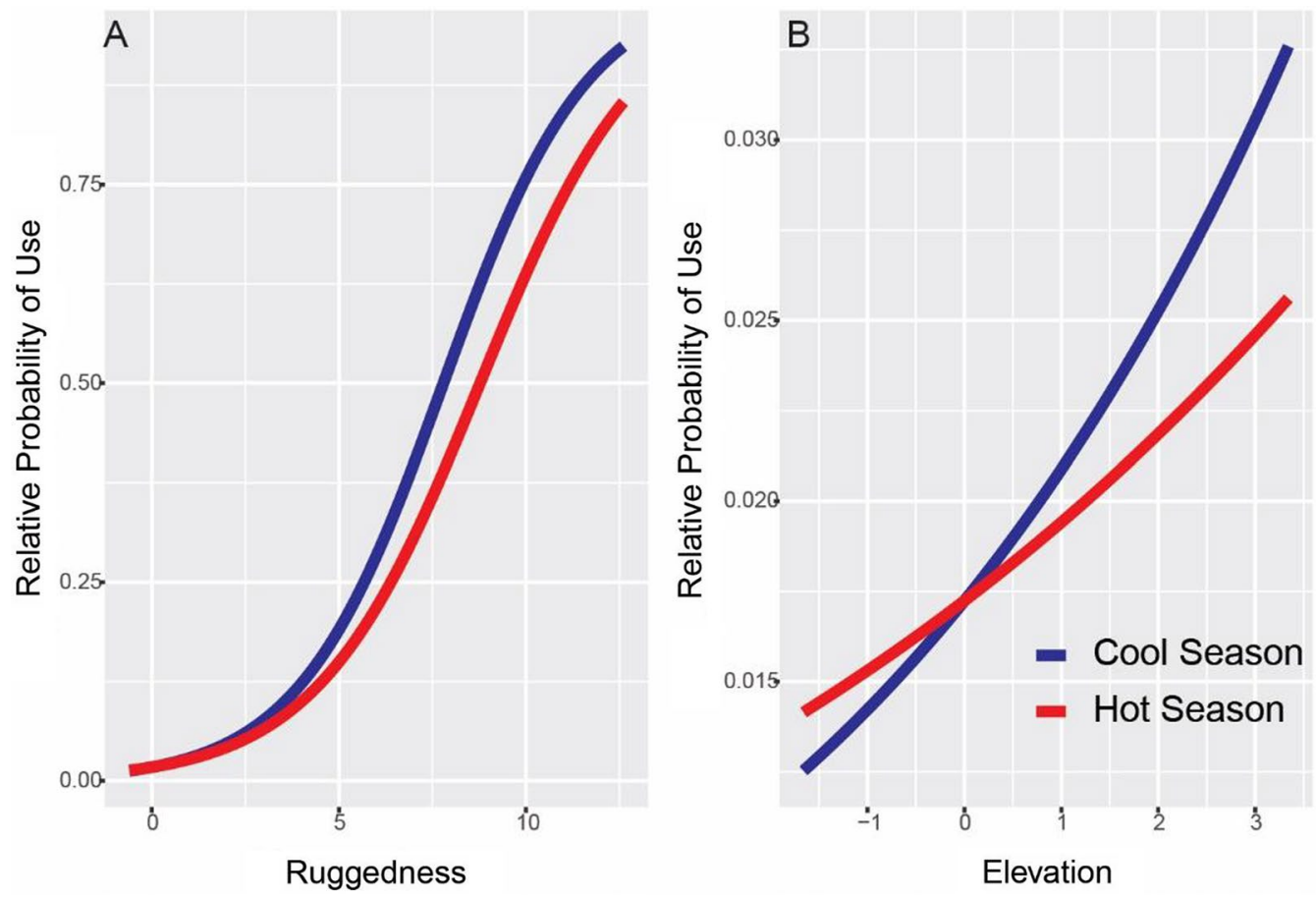

Fig. 2 The relative probability of use by bobcats on Kofa National Wildlife Refuge as ruggedness increase away from average for hot and cool seasons, while elevation is held constant at the average for used and unused points (A). The relative probability of use as elevation changes for both hot and cool season while ruggedness is held constant at the average for used and unused points (B). The $x$-axis for both are scaled as multiples of the standard deviation away from the average, which is at 0 . The extent of the $x$-axis is bounded by the maximum and minimum of each variable of observed values

The MiSeq run resulted in a total of 5,884,850 raw sequence reads. After trimming, filtering, denoising, and chimera removal with DADA2, a total of 989,861 reads remained; 594,316 belonging to $12 \mathrm{~S}$ and 395,545 belonging to $16 \mathrm{~S}$. Clustering at $97 \%$ similarity resulted in a total of 32 OTUs for $12 \mathrm{~S}$ and 20 sOTUs for $16 \mathrm{~S}$. Naïve lowest common ancestor analysis [23] following BLAST identified 29 of the $12 \mathrm{~S}$ sOTUs, and 17 of the $16 \mathrm{~S}$ sOTUs (Additional file 1: Table S2) resulting in 7 oOTUs for $12 \mathrm{~S}$ and 11 oOTUs for $16 \mathrm{~S}$ (Additional file 1: Table S2) after felid OTUs presumably for bobcat were removed. Samples were identified to genus or lower for $28 \%$ of $12 \mathrm{~s}$ oOTUs and $50 \%$ of $16 \mathrm{~s}$ oOTUs (Additional file 1: Table S2). Once oOTUs that were identified by both markers were unified, 12 dietary items were detected (Table 4). Within the 31 bobcat scats, members of the order Rodentia were in 28, Passeriformes in 21, lagomorphs in 8, and non-bobcat Carnivora in 6. All non-bobcat Carnivora dietary items were of the family Canidae; we were unable to identify one beyond family and 5 of the 6 were Urocyon (Table 4).

\section{Discussion}

Our results illuminate bobcat ecology in a harsh desert climate. Bobcats on Kofa appear to utilize rugged terrain and higher elevations, and consume mostly small prey items. Bobcats also show seasonal variation in space and habitat use; they avoid rugged terrain at higher elevations during the cool season and decrease their home-range size during the hot season. Concurrent sampling strategies and the use of modern technology in diet analysis allowed for these conclusions despite harsh sampling conditions impeding our design and sampling efforts.

Our study is one of only a few to examine home ranges and space use of desert bobcats $[3,9,10]$, leaving much room for further exploration of bobcats in hot, arid climates. The female home ranges in this study were substantially smaller $\left(16.0 \mathrm{~km}^{2} \pm 1.0 \mathrm{SE}\right)$ than an average of 29 studies of bobcat space use in their more northern range or for bobcats in the Chihuahuan Desert (23.9 $\mathrm{km}^{2} \pm 4.2 \mathrm{SE}, 27.1 \mathrm{~km}^{2} \pm 6.4 \mathrm{SE}$, respectively) [9]. While we are unable to generalize from the estimate of home-range size from one male, it is interesting to note the male was young and his home range size may have been larger than other males if he had not yet established a territory. Although our sample sizes were small 
Table 4 Organism operational taxonomic units (oOTU) identified to their lowest taxonomic level, common name of oOTUs (* denotes common name of probable species) and the number of bobcat scats (out of a total of 31 total bobcat scats collected at Kofa National Wildlife Refuge) in which each oOTU was identified. Two oOTU's were only identified to genus but had only one subordinate species known to be present within the study area. Each lowest oOTU is identified as being detected by the $12 \mathrm{~S}$ or $16 \mathrm{~S}$ marker (some were identified by both)

\begin{tabular}{|c|c|c|c|c|c|}
\hline Total diet oOTUs & Common name & Taxonomic level & \# scats & oOTUs 12S & oOTUS 16S \\
\hline Ammospermophilus harrisii & Harris antelope squirrel & Species & 1 & & Yes \\
\hline Chaetodipus baileyi & Bailey's pocket mouse & Species & 8 & Yes & Yes \\
\hline Chaetodipus californicus & California pocket mouse & Species & 1 & & Yes \\
\hline Neotoma lepida & Desert woodrat & Species & 2 & & Yes \\
\hline Mus (subgenus) & Mice & Subgenus & 1 & & Yes \\
\hline Lepus & Black-tailed jackrabbit* & Genus & 8 & & Yes \\
\hline Neotoma & Pack rats & Genus & 1 & & Yes \\
\hline Urocyon & Gray fox* & Genus & 5 & Yes & \\
\hline Canidae & Canids & Family & 1 & Yes & \\
\hline Cricetidae & $\begin{array}{l}\text { New World rats and mice, hamsters, } \\
\text { voles, lemmings }\end{array}$ & Family & 8 & & \\
\hline Muroidea & Mice, rats, voles, hamsters, gerbils & Super family & 17 & & Yes \\
\hline Passeriformes & Perching birds & Order & 21 & Yes & Yes \\
\hline
\end{tabular}

and limit our power to generalize our gross home-range size findings, the within-individual comparison of seasonal home-range size supports our expectations regarding movement reductions in the hot season. There was a substantial and significant reduction in home-range size between the cool $\left(20.2 \mathrm{~km}^{2} \pm 2.6 \mathrm{SE}, 13.5{ }^{\circ} \mathrm{C}\right)$ and hot seasons $\left(11.9 \mathrm{~km}^{2} \pm 0.8 \mathrm{SE}, 33^{\circ} \mathrm{C}\right)$. This differs from the lack of a significant difference in seasonal homerange size between bobcats in the Chihuahuan Desert and studies of more northern populations [9]; however, the portion of the Chihuahuan Desert sampled averaged $9{ }^{\circ} \mathrm{C}$ cooler in the winter and $5{ }^{\circ} \mathrm{C}$ cooler in the summer compared to the Sonoran Desert. The smaller home ranges that we found in the hot season suggest bobcats in extremely hot climates reduce their movements seasonally in response to increases in temperature, which has also been observed in other carnivore species [24]. We hypothesize that this response is due to a reduction of available surface water and an increase in water needs for long-distance movement and thermoregulation. Future studies on desert-dwelling bobcats that can compare between sexes and age classes would elucidate the relationship between water, thermoregulation, and space use. Unfortunately, we were unable to accomplish this analytical step due to our limited sample size.

In addition to small sample size, another limitation to our analysis is that we only recorded locations during crepuscular and nocturnal time periods that may have biased our assessment of space use. However, previous research has found that the vast majority of desert bobcat movement takes place during these time periods [9, 10]. Therefore, it is highly unlikely that the exclusion of daytime locations prevented the detection of movements that would alter home-range size estimates.

Although our camera grid provided reasonable detection rate for an elusive carnivore, the models failed to adequately describe occupancy trends; however, thirdorder habitat selection from GPS-collar data provided some insight into habitat use of desert bobcats. Bobcats favored higher elevations or rugged terrain at lower elevations. While results of our top model should be considered cautiously because of the low sample size of GPS-collared bobcats, selection of rugged terrain and higher elevations by bobcats in this environment is realistic. Bobcats may use rugged terrain to avoid humans, who are more likely to use lower elevations and less rugged terrain (e.g., [25]), avoid coyotes [26], or to follow prey distribution [27]). Bobcat preference for higher elevations is likely to seek out cooler temperatures, while avoiding high elevation rugged terrain that would be energetically costly to traverse and relatively absent of vegetative cover. During the hot season, the cooler temperatures found at higher elevations likely outweigh the costs of using higher elevation rugged terrain. Within the home ranges of the four GPS-collared bobcats, low-elevation, rugged terrain (i.e., mostly dry washes in the flatlands between mountain ranges) were likely utilized as travel corridors and rest locations. These washes provide the only meaningful cover on the lower elevation landscape for both bobcats and their prey. This finding aligns with previous research that has looked at desert bobcat space use [3].

It is interesting that ruggedness appeared in our top models even though we did not initially capture the 
bobcats in rugged or high terrain. For timely animal processing and release, we limited live trapping to lower, less rugged terrain with almost no opportunities to set traps in higher, rugged terrain that was more commonly accounted for within the camera-trap survey. Had detection been higher within the camera-trap grid, it would have been possible to examine habitat use of bobcats who were exposed to more rugged terrain in high elevation. This limitation supports the need to account for the elusive nature of carnivores and the need for longer sampling periods and complimentary sampling methodologies to obtain information on space use by desert carnivores.

Our study contributes to the growing body of literature using metabarcoding for diet analysis and is the first to utilize this technique for bobcats. Nearly all scats collected included Rodentia DNA (83\%) and more than two-thirds of scats collected included Passeriformes DNA (68\%). Frequency of occurrence of rodents was similar to that observed in other bobcat populations $[1,11,12,28$, 29]. Slightly larger prey items such as Urocyon and Lepus species were detected in $\leq 25 \%$ of scats. However, these larger prey items were not detected in scat in absentia of DNA from other prey items, suggesting that capture of these larger prey items was opportunistic while pursuing a diverse prey base. It is also possible that foxes were detected by metabarcoding because they urinated on top of bobcat scats, and were not in fact a prey item. This behavior has been demonstrated in coyotes contaminating scats of cougars (Puma concolor) [30]. We did not detect any larger-bodied species such as desert bighorn sheep or mule deer, despite scats being collected during fawning and lambing seasons [31, 32]. Consistent with our results, deer likely represents only a minor food item in desert regions $[1,33]$, even though studies in more northern climates show deer to represent a more substantial food item in bobcat diet [12, 29]. Our findings on Kofa also support previous studies' findings that bobcats were likely not a source of mortality for desert bighorn sheep [32]. This may be important to bighorn sheep management.

The main difference between our diet findings and previous studies is the high relative frequency of avian species. In previous studies, bird species were limited mostly to $<10 \%$ of relative frequency and, at most, $31 \%$ of relative frequency $[1,11,12,28,29]$. These differences could be due to differences in foraging strategies among bobcat populations, or the differences in methodology that were used to detect prey [33]. Previous research has suggested that smaller animals, such as birds, have the largest potential for error in traditional morphology-based, postingestion diet analysis $[17,33]$ because they are digested beyond the ability for visual identification. Therefore, we believe that the higher proportion of avian species in our diet analysis is likely due to improved detection rather than higher consumption rates compared to other environments. Notably, we were able to assign most sequence reads at the species or genus level with both markers for mammalian prey. However, we were only able to assign avian reads at the order level. Although the pan-vertebrate $12 \mathrm{~S}$ marker used in this study seems to amplify avian prey well, this marker appears to have poor taxonomic power for assigning reads at higher taxonomic levels for birds. The region of $12 \mathrm{~S}$ mitochondrial DNA targeted by this marker appears to have little variability within avian species, and particularly for species within the order Passeriformes. Thus, family, genus, and species level assignments were not possible using this marker. Given this limitation, future studies should consider adding an additional, avian-specific marker if more precise taxonomic identity of avian prey is desired. Increased use of metabarcoding for diet analysis is needed to further explore differences between ecosystems versus differences between sampling methodologies.

\section{Conclusions}

In this study, we found that desert bobcats have smaller home ranges that vary seasonally and consume little to no large prey items relative to bobcats studied in more northern regions. The use of new technology allowed for identifying previously undercounted diet items (i.e., avian species in bobcat diet) that can be important for understanding the totality of bobcat predation and specialization. We encourage other researchers to combine multiple, modern techniques when conducting field studies, especially in regard to studies of rare and elusive species in harsh environments. Extending the sampling period to would likely also be beneficial. The differences in space use and diet we observed were only possible through the use of multiple field and laboratory techniques and likely reflect adaptations to living in a harsh environment.

\section{Methods}

\section{Study area}

Kofa National Wildlife Refuge (hereafter referred to as Kofa) is located in southeastern Arizona, USA (Fig. 1), with an annual average rainfall of $10 \mathrm{~cm}$, an annual mean temperature of $22{ }^{\circ} \mathrm{C}$, and an average monthly maximum of $37^{\circ} \mathrm{C}$ [22]. Kofa is sparsely vegetated with desert-adapted species. The refuge includes two mountain ranges, the Kofa Mountains and the Livingston Hills, with relatively flat lowlands between them. Terrain features were of particular interest in this study as the availability of escape terrain has been identified as an important influence on the space use of potential prey 
species in the area [28]. Multiple potential prey species for bobcats exist including 19 species of Rodentia and two species of Lagomorpha, desert bighorn sheep (Ovis canadensis mexicana), Sonoran pronghorn (Antilocapra americana sonoriensis), and mule deer (Odocoileus hemionus), and over 150 species of birds.

\section{Trapping}

We set traps for bobcats on Kofa in the lowlands between the Kofa Mountains and the Livingston Hills during the cool season of 2016-2017. All bobcats were captured in accordance with Arizona Game and Fish Department (AZGFD) permits and protocols, by AZGFD personnel, utilizing Victor $3 \mathrm{~N}$ soft-catch foot-hold traps equipped with remotely enabled trap alerts that notified personnel when a trap was tripped. Additionally, all traps were visually checked every $12-24 \mathrm{~h}$. Traps were placed near dirt roads to ensure quick access when a trap-closed alert was sent and spaced to capture bobcats likely to have neighboring home ranges. Captured animals were chemically immobilized utilizing a combination of ketamine $(10 \mathrm{mg} / \mathrm{kg})$ and xylazine $(1.5 \mathrm{mg} / \mathrm{kg})$ [16]. Once immobilized, each bobcat was fitted with a GPS-enabled collar equipped with remote upload (Vectronic Aerospace, Berlin Germany). Collars were scheduled to take daily locations every $4 \mathrm{~h}$ between $8 \mathrm{pm}$ and 8 am to capture nocturnal movement while sustaining battery power for at least 1 year.

\section{Camera trapping}

We also deployed camera traps on a 2-km grid across $\sim 300 \mathrm{~km}^{2}$ of Kofa. The grid included all elevations and terrain types. Two game cameras (Browning Strikeforce HD Pro X) were placed opposing each other across likely wildlife trails within each grid cell while maintaining relational spacing with other cameras (Fig. 1). Camera were set to a burst of three photographs with a 30-s delay between bursts and have Infrared LED for nighttime photographs. Cameras were active at each site for 5 weeks, which constituted a camera-trap session. Cameras were deployed in three successive 5-week intervals, to allow for logistical and resource constraints, resulting in all 69 grid points were sampled during the cool season (December 2016 and May 2017).

\section{Home-range estimations and resource selection}

Location data obtained from the GPS collars in 2017 were used in a mixed effect model of third order resource selection (individual selection within their home range) [34]. The first $72 \mathrm{~h}$ of location data from each individual was removed to avoid any anomalous post-capture movements. All fixes with a dissolution of precision $\geq 10$ were removed [35]. Terrain values (elevation and ruggedness: the absolute mean difference between the elevation of a cell and its surrounding cells [36]) were extracted and calculated from USGS elevation data aggregated in the terrain data set available from ESRI at a $30-\mathrm{m}$ resolution [37]. Variables were evaluated for correlation with a variance inflation factor threshold of ten to prevent collinearity in model slopes [38]. Location-specific values were extracted from these layers for each collar location, all values were standardized (mean $=0, S D=1$ ) using all used and unused values to aid in model convergence. Home ranges were generated for each individual utilizing a 95\% kernel utilization distribution [39] an $\mathrm{h}_{\text {ref }}$ bandwidth estimator was used to reduce fragmentation of the home range [39]. Home ranges were estimated with the package adehabitatHR in the $\mathrm{R}$ environment [40, 41]. Terrain variables were extracted for each home range at 30-m intervals to quantify third order available habitat, this resulted in greater than 14 available points to every used point for the four individuals. Land cover within the home ranges where third-order habitat selection was being assessed was homogenous with over $99.7 \%$ being classified as shrub/scrub at a $30-\mathrm{m}$ resolution by the National Land Cover Database [42]. Multiple binomial mixed effect (used vs available) models were generated to explore the effect of terrain features on third-order habitat selection using the lme4 package in $\mathrm{R}$ [43]. All models included random intercepts and slopes to account for individual variation in habitat use and home-range size and composition [44, 45]. Perennial water sources were removed from consideration because mapped perennial water sources only existed within the home range of a single collared bobcat, therefore lacking replication. Additionally, water resources of the other three bobcats (and possibly additional sources for the one that overlapped a mapped water source) were likely unmapped or ephemeral sources that could not be accounted for in this analysis. The models that produced significant fixed effects $(\alpha=0.05)$ were then evaluated using Akaike's Information Criterion, corrected for small sample size (AICc) [46] to select a top model for inference.

\section{Occupancy modeling}

Occupancy modeling was carried out in program RMark $[41,47]$ utilizing data from the camera trap grid to establish occupancy across all of Kofa. Elevation and ruggedness data were generated from the same sources using the same methods as used for the GPS-collar data. Ruggedness and elevation were then averaged over $510 \mathrm{~m}$ to characterize the terrain traveled through to reach the camera as well as the immediate terrain. Values were standardized to deviation from the values mean as a multiple of the standard deviation to aid in model convergence. Single season occupancy models were then generated utilizing terrain factors that could influence 
detection and occupancy [48]. Models were evaluated utilizing both 30- and 510-m resolutions of ruggedness and elevation in varying combinations. Models were evaluated for significant fixed effects at a $\alpha$ of 0.05 .

\section{Diet analysis}

Within each cell of the camera grid, a likely travel corridor (e.g., road, trail, dry creek bed) was identified and utilized as a representative 1-km transect for the cell. Each transect was first cleared of all carnivore scats prior to the experimental period to ensure only fresh scat were collected, then walked once. All collected scats were frozen and stored in a $-20{ }^{\circ} \mathrm{C}$ freezer to preserve DNA quality. Extraction of DNA for species identification was carried out using Qiagen stool kits following a protocol modified from the manufacturer's standard protocol (Qiagen Inc., Valencia CA, Appendix 1). Each scat was identified to carnivore species by sequencing a 126 bp mini-barcode fragment or the mitochondrial gene ATP6 [49]. Once species was confirmed, a second extraction was run on each bobcat scat using a homogenized cross-section of the scat to better capture prey DNA (Appendix 1).

In order to genetically identify prey items from scat, we performed DNA metabarcoding [50]. Libraries for nextgeneration sequencing were prepared using a two-step PCR protocol for two loci: a mammal-specific primer set (16Smam1, 16Smam2) [51] targeting 130-138 bp (including primers) of the mitochondrial $16 \mathrm{~S}$ rRNA locus, and a pan-vertebrate primer set (12SV5F, 12SV5F) [52] targeting 140-143 bp (including primers) of the mitochondrial $12 S$ locus. Initial PCR Reactions were conducted in duplicate for each locus, with one replicate containing bobcat-blocking primers designed for this study and one replicate containing no bobcat-blocking primers. All replicates contained human blocking primers. Replicates from the initial PCR for each sample were pooled prior to the second PCR used to add dual indexes for sample identification. Information on primers and PCR conditions can be found in Appendix 1. Samples were then sequenced on an Illumina MiSeq with a 300 cycle V2 micro kit.

Following demultiplexing, primer sequences were removed and $12 \mathrm{~S}$ and $16 \mathrm{~S}$ sequences were separated using CUTADAPT v. 1.18 [53]. Next, data were filtered, denoised, paired-ends were merged, and chimeras were removed with DADA2 [54] within the QIIME2 v. 2018.8 environment [55], and reads were truncated at $108 \mathrm{bp}$ (12S) and $94 \mathrm{bp}(16 \mathrm{~S})$. Sequences were then clustered into sequence operational taxonomic units (sOTU) at 97\% similarity using q2-vsearch in QIIME2. sOTUs were run through NCBI BLAST to identify probable assignments that were then analyzed using a naïve lowest common ancestor algorithm in MEGAN [23] to assign an organism operational taxonomic unit (oOTU).

Abbreviations

GPS: Global Positioning System; Kofa: Kofa National Wildlife Refuge; oOTU: Organism operational taxonomic units; sOTU: Sequence operational taxonomic units.

\section{Supplementary Information}

The online version contains supplementary material available at https://doi. org/10.1186/s12862-022-01973-3.

Additional file 1: Table S1. Occupancy model results from camera traps. Table S2. BLAST \# constructed from biom file.

Additional file 2. DNA extraction modifications from Qiagen Qiaamp DNA Stool mini Kit instructions.Modifications listed by corresponding step from Qiagen instructions, un-listed steps remain unchanged.

Additional file 3: Additional Data. All raw data and details from camera trap models are available as Additional file 3.

\section{Acknowledgements}

We thank the U.S. Fish and Wildlife Service and the Arizona Game and Fish Department for their assistance in data collection and access to the Kofa National Wildlife Refuge. We would like to specifically thank C. Weise of the U.S. Fish and Wildlife Service for logistical support, B. Jansen of the Arizona Game and Fish Department for capture support, and T. Carver for collection of field data. Any use of trade, firm, or product names is for descriptive purposes only and does not imply endorsement by the U.S. Government. The findings and conclusions in this publication are those of the authors and should not be construed to represent any official USDA or U.S. Government determination or policy.

\section{Authors' contributions}

JKY contributed to the conception and design of the study. JD and TR analyzed and interpreted data. All authors read and approved the final manuscript.

\section{Funding}

This research was supported by the U.S. Department of Agriculture, National Wildlife Research Center and the U.S. Fish and Wildlife Service, Kofa National Wildlife Refuge. Neither funding body played a role in study design, data collection, analysis, and interpretation of data or in writing. Funding supported supplies, travel, and salaries.

\section{Availability of data and materials}

All data generated or analysed during this study are included in this published article in its Additional files 1, 2, 3.

\section{Declarations}

Ethics approval and consent to participate

All procedures were approved by the USDA, National Wildlife Research Center Institute for Animal Care and Use Committee (QA-2703).

\section{Consent for publication}

Not applicable.

\section{Competing interests}

The authors declare that they have no competing interests.

\section{Author details}

${ }^{1}$ Ecology Center, Utah State University, Logan, UT 84322, USA. ${ }^{2}$ Present Address: Department of Wildland Resources, Utah State University, Logan, UT 84322, USA. ${ }^{3}$ U.S. Department of Agriculture, National Wildlife Research Center - Predator Research Facility, Millville, UT 84326, USA. 
Received: 17 January 2021 Accepted: 9 February 2022 Published online: 04 March 2022

\section{References}

1. López-Vidal JC, Elizalde-Arellano C, Hernández L, Laundré JW, GonzálezRomero A, Cervantes FA. Foraging of the bobcat (Lynx rufus) in the Chihuahuan Desert: generalist or specialist? Southwest Nat. 2014;59:157-66.

2. Koehler GM, Hornocker MG, Journal S, May N. Seasonal resource use among mountain lions, bobcats, and coyotes. J Mammal. 2008;72:391-6.

3. Lawhead DN. Bobcat (Lynx rufus) home range, density and habitat preference in South-Central Arizona. Southwest Nat. 1984:29:105.

4. Tucker SA, Clark WR, Gosselink TE. Space use and habitat selection by bobcats in the fragmented landscape of South-Central lowa. J Wildl Manag. 2008;72:1114-24.

5. LovalloAnderson MJEM. Bobcat (Lynx rufus) home range size and habitat use in Northwest Wisconsin. Am Midl Nat. 1996;135:241-52.

6. Nielsen CK, Woolf A. Habitat-relative abundance relationship for bobcats in southern Illinois. Wildl Soc Bull. 2002;30:222-30.

7. Chamberlain MJ, Leopold BD, Conner LM. Space use, movements and habitat selection of adult bobcats (Lynx rufus) in Central Mississippi. Am Midl Nat. 2003;149:395-405.

8. Kirby JD, Rutledge JC, Jones IG, Conner LM, Warren RJ. Effects of time of day and activity status on bobcat (Lynx rufus) cover-type selection in Southwestern Georgia. Southeast Nat. 2010;9:317-26.

9. Elizalde-Arellano C, Lopez-Vidal JC, Hernandez L, Laundre JW, Cervantes FA, Alonso-Spilsbury M. Home range size and activity patterns of bobcats (Lynx rufus) in the southern part of their range in the Chihuahuan Desert, Mexico. Am Midl Nat. 2012;168:247-64.

10. Harrison RL. Ecological relationships of bobcats (Lynx rufus) in the Chihuahuan Desert of New Mexico. Southwest Nat. 2010;55:374-81.

11. Tewes ME, Mock JM, Young JH. Bobcat predation on quail, birds, and mesomammals. In: Quail V: proceedings of the fifth national Quail symposium. Texas Parks and Wildlife. Department, Austin, TX. 2002; p. 65-70.

12. Rose C, Prange S. Diet of the recovering Ohio bobcat (Lynx rufus) with a consideration of two subpopulations. Am Midl Nat. 2015:173:305-17.

13. Hass CC. Competition and coexistence in sympatric bobcats and pumas. J Zool. 2009;278:174-80

14. Litvaitis JA, Harrison DJ. Bobcat-coyote niche relationships during a period of coyote population increase. Can J Zool. 1989;67:1180-8

15. Mackay P, Long RA, Ray J, Zielinski W. Noninvasive survey methods for carnivores. Washington: Island Press; 2008.

16. Kreeger TJ, Arnemo JM. Handbook of wildlife chemical immobilization. 4th ed. Laramie; 2012. p. 448.

17. Litvaitis JA. Investigating food habits of terrestrial vertebrates. In: Boitani $L$, Fuller TK, editors. Research techniques in animal ecology: controversies and consequences. New York: Columbia University Press; 2000. p. 165-90.

18. Casper RM, Jarman SN, Deagle BE, Gales NJ, Hindell MA. Detecting prey from DNA in predator scats: a comparison with morphological analysis, using Arctocephalus seals fed a known diet. J Exp Mar Biol Ecol. 2007;347:144-54

19. Mumma MA, Adams JR, Zieminski C, Fuller TK, Mahoney SP, Waits LP. A comparison of morphological and molecular diet analyses of predator scats. J Mammal. 2016:97:112-20.

20. Rodgers TW, Janečka JE. Applications and techniques for noninvasive faecal genetics research in felid conservation. Eur J Wildl Res. 2013;59:1-16

21. Monterroso P, Godinho R, Oliveira T, Ferreras P, Kelly MJ, Morin DJ, et al. Feeding ecological knowledge: the underutilised power of faecal DNA approaches for carnivore diet analysis. Mamm Rev. 2019;49:97-112.

22. National Oceanic and Atmospheric Administration. 2018. https://www. weather.gov. Accessed 12 Oct 2018.

23. Huson DH, Beier S, Flade I, Górska A, El-Hadidi M, Mitra S, et al. MEGAN community edition -interactive exploration and analysis of large-scale microbiome sequencing data. PLoS Comput Biol. 2016;12:1-12.

24. Pomilia MA, McNutt JW, Jordan NR. Ecological predictors of African wild dog ranging patterns in northern Botswana. J Mammal. 2015:96:1214-23.

25. MCNitt DC, Alonso RS, Cherry MJ, Fies ML, Kelly MJ. Sex-specific effects of reproductive season on bobcat space use, movement, and resource selection in the Appalachian Mountains of Virginia. PLoS ONE. 2020;15(8):e0225355

26. Witczuk J, Pagacz S, Gliwicz J, Mills LS. Niche overlap between sympatric coyotes and bobcats in highland zones of Olympic Mountains, Washington. J Zool. 2015:297(3):176-83.

27. Godbois IA, Conner LM, Warren RJ. Space-use patterns of bobcats relative to supplemental feeding of northern bobwhites. J Wildl Manag. 2004;68(3):514-8

28. McKinney T, Smith TW. Diets of sympatric bobcats and coyotes during years of varying rainfall in Central Arizona. West N Am Nat. 2007;67:8-15.

29. McLean ML, McCay TS, Lovallo MJ. Influence of age, sex and time of year on diet of the bobcat (Lynx rufus) in Pennsylvania. Am Midl Nat. 2005;153:450-3.

30. DeMatteo KE, Blake LW, Young JK, Davenport B. How behavior of nontarget species affects perceived accuracy of scat detection dog surveys. Sci Rep. 2018:8:1-11.

31. Hoglander C, Dickson BG, Rosenstock SS, Anderson JJ. Landscape models of space use by desert bighorn sheep in the Sonoran Desert of southwestern Arizona. J Wild Manag. 2015;79:77-91.

32. McKinney T, Smith TW, Debos JC. Evaluation of factors potentially influencing a desert bighorn sheep population. Wildl Monogr. 2006;164:1-36.

33. Morin DJ, Higdon SD, Holub JL, Montague DM, Fies ML, Waits LP, Kelly MJ. Bias in carnivore diet analysis resulting from misclassification of predator scats based on field identification. Wildl Soc Bull. 2016;40(4):669-77.

34. Johnson $\mathrm{DH}$. The comparison of usage and availability measurements for evaluating resource preference. Ecology. 1980;61:65-71.

35. D'Eon RG, Delparte D. Effects of radio-collar position and orientation on GPS radio-collar performance, and the implications of PDOP in data screening. J Appl Ecol. 2005;42:383-8.

36. Wilson MFJ, O'Connell B, Brown C, Guinan JC, Grehan AJ. Multiscale terrain analysis of multibeam bathymetry data for habitat mapping on the continental slope. Mar Geod. 2007;30:3-35.

37. ESRI. ESRI:Terrain. https://www.esri.com; 2017.

38. Dormann CF, Elith J, Bacher S, Buchmann C, Carl G, Carr G, et al. Collinearity: a review of methods to deal with it and a simulation study evaluating their performance. Ecography (Cop). 2012;36:27-46.

39. Worton BJ. Kernel methods for estimating the utilization distribution in home-range studies. Ecology. 1989;70:164-8.

40. Calenge $C$. The package adehabitat for the $R$ software: tool for the analysis of space and habitat by animals. Ecol Model. 2006;197:1035.

41. R Core Team. R: A language and environment for statistical \#\# computing. R Foundation for Statistical Computing, Vienna,Austria. https://www.Rproject.org/. 2019.

42. Homer CG, Dewitz JA, Yang L, Jin S, Danielson P, Xian G, et al. Completion of the 2011 National Land Cover Database for the conterminous United States-representing a decade of land cover change information. Photogramm Eng Remote Sens. 2015;81:345-54

43. Bates D, Maechler M, Bolker B, Walker S. Fitting linear mixed-effects models using Ime4. J Stat Softw. 2015;67(1):1-48.

44. Gillies CS, Hebblewhite M, Nielsen SE, Krawchuk MA, Aldridge CL, Frair JL, et al. Application of random effects to the study of resource selection by animals. J Anim Ecol. 2006;75:887-98.

45. Muff S, Signer J, Fieberg J. Accounting for individual-specific variation in habitat-selection studies: efficient estimation of mixed-effects models using Bayesian or frequentist computation. J Anim Ecol. 2019;89:80-92.

46. Burnham KP, Anderson DR. Model selection and multimodel inference: a practical information-theoretic approach. 2nd ed. NY: Springer-Verlag. 2002.

47. Laake J. RMark: An R Interface for Analysis of Capture-Recapture Data with MARK. AFSC Processed Rep. 2013-01, Alaska Fish. Sci. Cent., NOAA, Natl. Mar. Fish. Serv., Seattle, WA. http://www.afsc.noaa.gov/Publications/ ProcRpt/PR2013-01.pdf. 2013.

48. MacKenzie DI, Nichols JD, Lachman GB, Droege S, Royle AA, Langtimm $C A$, et al. Estimating site occupancy rates when detection probabilities are less than one. Ecology. 2002;83:2248-55.

49. Chaves PB, Graeff VG, Lion MB, Oliveira LR, Eizirik E. DNA barcoding meets molecular scatology: short mtDNA sequences for standardized species assignment of carnivore noninvasive samples. Mol Ecol Resour. 2012;12:18-35

50. Shehzad W, Riaz T, Nawaz MA, Miquel C, Poillot C, Shah SA, et al. Carnivore diet analysis based on next-generation sequencing: application 
to the leopard cat (Prionailurus bengalensis) in Pakistan. Mol Ecol. 2012;21:1951-65.

51. Boessenkool S, Epp LS, Haile J, Bellemain E, Edwards M, Coissac E, et al. Blocking human contaminant DNA during PCR allows amplification of rare mammal species from sedimentary ancient DNA. Mol Ecol. 2012;21:1806-15.

52. Riaz T, Shehzad W, Viari A, Pompanon F, Taberlet P, Coissac E. ecoPrimers: inference of new DNA barcode markers from whole genome sequence analysis. Nucleic Acids Res. 2011;39:e145-e145.

53. Martin M. Cutadapt removes adapter sequences from high-throughput sequencing reads. EMBnet J. 2011;17:10.

54. Callahan BJ, McMurdie PJ, Rosen MJ, Han AW, Johnson AJA, Holmes SP. DADA2: high-resolution sample inference from Illumina amplicon data. Nat Methods. 2016;13:581.

55. Caporaso JG, Kuczynski J, Stombaugh J, Bittinger K, Bushman FD, Costello EK, et al. QIIME allows analysis of high-throughput community sequencing data. Nat Methods. 2010;7:335-6.

\section{Publisher's Note}

Springer Nature remains neutral with regard to jurisdictional claims in published maps and institutional affiliations.

- fast, convenient online submission

- thorough peer review by experienced researchers in your field

- rapid publication on acceptance

- support for research data, including large and complex data types

- gold Open Access which fosters wider collaboration and increased citations

- maximum visibility for your research: over $100 \mathrm{M}$ website views per year

At BMC, research is always in progress.

Learn more biomedcentral.com/submissions 